\title{
¿Con qué, por qué y contra qué hacemos? Tensiones, encrucijadas y potencias del hacer artístico ¿independiente?, ¿autogestivo?, ¿enredado?
}

Mariana del Mármol

IdHICS, FaHCE, UNLP/CONICET, Argentina

marianadelmarmol@gmail.com

Mariana Sáez

IdHICS, FaHCE, UNLP/CONICET, Argentina

marianasaezsaez@gmail.com

Fecha de recepción: 25/03/2020. Fecha de aceptación: 05/05/2020.

\begin{abstract}
Resumen
La ciudad de La Plata, capital de la provincia de Buenos Aires, se caracteriza por una importante actividad artística y cultural, gran parte de la cual se produce en un circuito que se autodefine como independiente o autogestivo. En este trabajo nos proponemos abordar algunas de las problemáticas y contradicciones relativas a las condiciones y estrategias de producción llevadas adelante en este circuito por medio del análisis de un caso concreto: un festival de Danza Contemporánea, Performance y Acciones Transdisciplinarias a cargo de un grupo de bailarinxs que inscriben su tarea en la autogestión. El análisis de este caso forma parte de un abordaje etnográfico del campo de las artes escénicas platenses que hemos desarrollado de manera complementaria en trabajos anteriores y busca funcionar como ejemplo de algunas de las lógicas de funcionamiento del circuito que nos encontramos indagando.
\end{abstract}

Palabras clave: Trabajo artístico, (auto)precarización, danza contemporánea, autogestión, financiamiento de las Artes Escénicas

What Do We Do? Why and Against What Do We Do it? Tensions, Crossroads and Potencies of (Independent? Self-Managed? Tangled?) Artistic Doing

\footnotetext{
Abstract

La Plata -the capital city of Buenos Aires province- is characterized by an important artistic and cultural activity, much of which occurs in a circuit that defines itself as
} 
independent or self-managed. In this paper we will address some of the problems and contradictions related to the production conditions and strategies of this circuit, based on a concrete case: a Festival of Contemporary Dance, Performance and Transdisciplinary Actions organized by a self-managed group of dancers. This case study is part of an ethnographical approach to the field of performing arts in La Plata which we have presented in previous works, and it is an example to show some of the logics of the circuit we are inquiring.

Keywords: Artistic Work, (Self)Precarization, Contemporary Dance, Self-Management, Financing of the Performing Arts.

La ciudad de La Plata, capital de la provincia de Buenos Aires, se caracteriza por una importante actividad artística y cultural, gran parte de la cual se produce en un circuito que se autodefine como independiente o autogestivo (del Mármol, Magri y Sáez, 2017).

En los últimos años, estas nociones, centrales en la construcción indentitaria de lxs artistas platenses, comenzaron a ser objeto de frecuentes cuestionamientos que abrieron un importante abanico de preguntas: ¿hasta qué punto es posible hablar de un hacer realmente independiente o autogestivo? ¿Cuál es la red de relaciones que sostiene este hacer? ¿Qué rol ocupan las instituciones del Estado en esa configuración? ¿Qué tipo de interacciones y conflictos emergen de la definición de los participantes de este circuito como artistas y como trabajadorxs? ¿Qué tipo de tensiones surgen entre creación y producción? ¿Cuáles entre trabajo y militancia? ¿Qué impulsa el hacer artístico independiente? ¿Qué pasaría si se detuviera este hacer?

En este trabajo nos proponemos abordar algunas de estas problemáticas y contradicciones por medio del análisis de un caso concreto: Danzafuera, un festival de Danza Contemporánea, Performance y Acciones Transdisciplinarias que se realiza en La Plata desde 2013, cuya idea y organización está a cargo de un grupo de bailarinxs que inscriben su tarea en la autogestión (Merlos y Sáez, 2016, 2017).

En otros trabajos (Sáez, 2016, 2018; del Mármol, Magri y Sáez, 2017; Basanta y del Mármol, 2017 y 2018; del Mármol, 2020), hemos hecho abordajes más generales de estos mismos problemas. En esta ocasión, nos interesa sumergirnos en el análisis de un caso específico y dar cuenta de las particulares decisiones, conflictos, estrategias y balances que se ponen en juego en el marco del mismo, con el objetivo de acercarnos al asunto en otra escala y echar luz sobre otras aristas.

Ambas autoras hemos participado en la organización del Festival en su segunda edición, luego de la cual una de nosotras continuó formando parte del equipo organizador en todas las ediciones y continúa haciéndolo en la actualidad. La otra, dejó de participar del equipo organizador, pero continuó vinculada al mismo en roles de colaboración o coordinación de espacios puntuales. De este modo, se trata de un caso que conocemos en detalle y del cual tenemos la posibilidad un acceso a los datos (de carácter tanto cualitativo como cuantitativo) que no tendríamos respecto de un espacio en el que no hubiéramos participado. Al mismo tiempo, las diferencias en la historia de cada una de nosotras en relación al Festival nos permiten complementar la mirada desde adentro que aporta una de nosotras con una mirada más extrañada que aporta la otra.

Este particular acceso al caso de análisis se complementa con un conocimiento del campo de las artes escénicas platenses a partir de sendas etnografías que ambas autoras venimos desarrollando en este ámbito, desde hace casi diez años, a partir de nuestras indagaciones doctorales (del Mármol, 2016; Sáez, 2017) y posdoctorales. Esta posición nos permite observar las decisiones, conflictos y estrategias que se han puesto 
en juego a lo largo de las distintas ediciones del Festival objeto de nuestro análisis como expresión de las lógicas de pensamiento, sentimiento y relación que caracterizan al campo de las artes escénicas platenses en los últimos años. No pretendemos entonces abordar el caso en su singularidad (aunque por supuesto observamos que la tiene), sino, por el contrario, tomarlo como un ejemplo de las lógicas de funcionamiento del circuito que nos encontramos indagando.

Comenzaremos presentando al Festival desde sus orígenes. Referiremos a los cambios en el equipo, las fuentes de financiamiento y la dinámica del Festival a lo largo de sus seis primeras ediciones. Describiremos las tareas involucradas en la organización y realización del Festival y sus cambios a través de los años.

A continuación, analizaremos algunos de los aspectos de la organización y el trabajo del Festival narrados en los apartados anteriores poniéndolos en relación con ideas propuestas por otrxs autorxs que han abordado cuestiones ligadas al trabajo artístico o creativo. Retomaremos las propuestas de Luc Bolstanski y Eve Chiapello (1999), Isabell Lorey (2006) y Bojana Kunst (2015 a y b) y sus definiciones sobre el carácter auto-precarizante del trabajo artístico y el hacer menos o dejar de hacer como modo de resistencia, y las pondremos en diálogo con representaciones sobre estos mismos asuntos que se pusieron en juego en ciertos espacios de encuentro y diálogo realizados dentro del propio Festival.

Señalaremos que algunas de estas propuestas implican pensar la producción artística desde una lógica diferente a la de la economía y en la que el reconocimiento es la principal moneda de cambio y observaremos que aún, cuando Danzafuera funciona en gran medida en base a esta otra lógica, gran parte de su organización implica balances económicos, consecución y distribución de fondos y mueve ciertos sectores de la economía a una escala cuya magnitud aún nos cuesta definir.

En el último apartado compartiremos en más detalle algunos datos relativos al modo en que se distribuye el dinero que circula a través del Festival con el objetivo de avanzar sobre la pregunta acerca de los recursos económicos invertidos y distribuidos en su realización, los sectores de la economía que se encuentran implicados y los modos en los que esta circulación implica relaciones del ámbito autogestivo tanto con el Estado como con el mercado.

Hemos procurado compartir algunos datos económicos y balances financieros que no suelen ser de fácil acceso o circulación, y dar cuenta de cuáles fueron las fuentes de financiamiento, qué porcentaje de recursos aportó cada una y en qué fueron gastados esos recursos. Consideramos que esto puede ser un primer paso hacia un análisis más riguroso del modo en que circulan los recursos en un circuito, cuya economía suele pensarse más a partir de las representaciones de sus integrantes que de datos numéricos concretos. No obstante, la aproximación a este tipo de análisis puso de manifiesto que gran parte de los recursos económicos y del valor que se pone en juego en la organización y el desarrollo de un festival (así como de otro tipo de eventos en este mismo circuito) excede lo monetario y que ese valor aún nos resulta difícil de ponderar.

\section{I}

Danzafuera es un Festival de Danza Contemporánea, Performance y Acciones Transdisciplinarias que se realiza anualmente en la ciudad de La Plata desde 2013. Fue creado por un grupo de bailarinxs y gestorxs platenses que sentían la necesidad de generar nuevos espacios y llegar a nuevos públicos desde la danza contemporánea. 
Surgió como un festival al aire libre en espacios urbanos de la ciudad de La Plata, comprendiendo a la misma como escenario para la producción artística y como paisaje a ser intervenido.

Desde sus inicios, el Festival, que ya cuenta con siete ediciones, fue impulsado de manera autogestiva. Una de las premisas que se mantuvo desde su origen fue garantizar el carácter gratuito de las obras para lxs espectadores y el pago de algún tipo de retribución para lxs artistas. Para poder sostener esta premisa, gran parte del trabajo de organización del Festival consiste en el desarrollo de diversas estrategias de financiamiento.

El impulso para la creación de Danzafuera surgió, en buena parte, de las discusiones que tuvieron lugar en una "Jornada de reflexión, diálogo y movimiento", organizada por ACIADIP (Asociación de Coreógrafos, Intérpretes y Afines de Danza Independiente Platense) a fines de 2012. En esta charla, en la que se dieron discusiones sobre autogestión y políticas culturales públicas comenzó a configurarse la idea de organizar un festival local, que permitiera visibilizar la producción de danza contemporánea en la ciudad y acercarla a nuevos públicos. Cabe señalar que ACIADIP es una asociación civil que reúne a diversos actores del campo de la danza de la ciudad de La Plata, con el objetivo de difundir la danza independiente de la región, fomentar su conocimiento, comunicabilidad, protección, preservación, promoción y desarrollo en sus diversas expresiones. Se creó en el año 2011, al calor de las primeras acciones del Movimiento por una Ley Nacional de Danza. Entre otras actividades realizadas en el transcurso de su primer año de funcionamiento, en diciembre de 2012 organizó la "Jornada de Reflexión, Diálogo y Movimiento sobre Danza Independiente" en el Centro Cultural Estación Provincial. La jornada tuvo dos instancias, una primera de mesa redonda integrada por Diana Rogovsky, Ale Cosin, Mariela Ruggieri, Daniela Camezzana y Adriana Falkemberg, y una segunda parte, en la que se realizó una improvisación colectiva en los andenes de la estación. Más información sobre esta jornada, y sobre la ACIADIP, en su sitio web: https://aciadip.wordpress.com/2013/02/12/breve-cronicade-la-jornada-de-reflexion-dialogo-y-movimiento-11-de-diciembre-de-2012-centrocultural-estacion-provincial/

Además de apoyar al Festival Danzafuera y otras iniciativas de sus socixs, ACIADIP lleva adelante su propio festival, denominado " 96 horas danza"; organiza ciclos, talleres, charlas y otras actividades; y participa y coordina espacios de intercambios de experiencias en otros marcos (como el Festival AÚRA, distintos encuentros y congresos vinculados a las artes escénicas, etc.).

La tarea fue encarada por cinco bailarinxs y gestorxs de la ciudad y, si bien contó con el apoyo de ACIADIP, se definió como un festival independiente a dicha agrupación. La denominación Danzafuera se vinculó a la decisión de realizar el Festival en espacios públicos al aire libre. Con el paso del tiempo, el nombre del Festival fue cargándose de otros sentidos vinculados al afuera de la danza, es decir, a una experimentación y exploración del cuerpo en movimiento que pueda poner en cuestión ciertos límites disciplinares (Merlos y Sáez, 2016). Durante los primeros cuatro años, cada edición del Festival tenía como locación dos parques o plazas que iban variando de año en año. En cada uno de estos espacios se realizaba una residencia de creación de dos semanas de duración, coordinada por artistas invitadxs que, en conjunto con un grupo de participantes seleccionados a partir de una convocatoria abierta, creaban una obra para ese espacio específico. El Festival se iniciaba con el desarrollo de estos procesos de residencias y culminaba en un fin de semana (a fines de noviembre o principios de diciembre) en el que se mostraban las obras resultantes de aquellos procesos junto con otras obras curadas por el equipo organizador del Festival, a partir de una convocatoria abierta. Si bien siempre se intentó contar con obras de 
otras ciudades e incluso internacionales, durante los primeros años la programación estuvo conformada predominantemente por obras de La Plata y la Ciudad Autónoma de Buenos Aires (CABA).

Durante estas primeras ediciones el formato del Festival fue prácticamente el mismo y el equipo relativamente estable. Cuatro de lxs cinco integrantes iniciales se mantuvieron de la primera a la cuarta edición, con el ingreso y egreso de nuevxs compañerxs y la sumatoria cada año de algunxs colaboradorxs que cumplian tareas puntuales en las semanas previas y durante el festival. Para la realización de las dos primeras no se contó con ningún tipo de subsidio, con lo cual, las principales fuentes de financiamiento fueron la venta de rifas, la contribución de auspiciantes (que aportaban pequeñas sumas de dinero u otros recursos a cambio de un espacio de publicidad en el programa y/o el sitio web del Festival) y la realización de fiestas. En la tercera y la cuarta se recibieron subsidios del Fondo Nacional de las Artes, se realizaron obras y talleres a beneficio del Festival y, en una de ellas, se realizó una campaña de crowdfunding. El crowdfunding, financiamiento colectivo o micromecenazgo, es un mecanismo para el financiamiento de proyectos a través de pequeños aportes económicos realizados por una gran cantidad de personas. Suele realizarse a través de plataformas de internet específicas para ello, que contribuyen a la comunicación y difusión de los proyectos, y aportan la infraestructura tecnológica para la realización de los aportes. En el caso particular del Festival Danzafuera, fue realizado a través del sitio web www.idea.me. Con el correr de estas ediciones, el Festival comenzó a construir una legitimación mayor y las estrategias de financiamiento se enfocaron en tareas más estrechamente vinculadas a la producción y gestión de danza, y se dejaron de lado otras (como la realización de fiestas y la venta de rifas).

Durante el 2017, por distintas razones, el equipo organizador se redujo considerablemente: en la quinta edición las organizadoras fueron tres, en la sexta, cuatro. Por otra parte, luego de recibirlo por dos años consecutivos, ese año no se obtuvo el subsidio del Fondo Nacional de las Artes. Es necesario señalar que el festival contó con el apoyo del Fondo Nacional de las Artes a través de las Becas para Proyectos Grupales, en las convocatorias 2014 (para la tercera edición del festival en el año 2015) y 2015 (para la cuarta edición del festival en el año 2016). A partir del año 2016 (primer llamado efectuado desde la gestión macrista) esta convocatoria a becas se orientó hacia los procesos de creación de obras, y el festival ya no obtuvo el apoyo. En estas condiciones, Danzafuera entró en crisis, y las integrantes que quedaron frente a su organización decidieron tomarse un tiempo para volver a pensar el Festival.

La primera decisión que se tomó fue modificar la fecha de realización del Festival, de noviembre a marzo. Las razones de este cambio fueron varias: la saturación de actividades propia de ese momento del año, ${ }^{1}$ la existencia de otros dos festivales de artes escénicas en la ciudad que también se realizaban en esas fechas. Nos referimos a Diagonales, Festival Internacional de Danza en Paisajes Urbanos, que se realizó en la ciudad de La Plata entre 2013 y 2017; y a AÚRA, Festival de Artes escénicas, que tuvo su primera edición en el año 2016, y lleva a la fecha cuatro ediciones realizadas. El hecho de que la fecha en la que se venía realizando resultaba incompatible con la posibilidad solicitar las ayudas para la realización de Festivales ofrecidas por el Programa de Cooperación Iberoamericana para las Artes Escénicas (Programa Iberescena) del cual participan Argentina, Bolivia, Brasil, Chile, Colombia, Costa Rica, Ecuador, El Salvador, España, México,

1 Entre los meses de diciembre y noviembre tienen lugar las muestras de talleres y seminarios, las presentaciones de Tesis de Ixs egresadxs de los profesorados en danza contemporánea y expresión corporal de la Escuela de Danzas Clásicas de La Plata, y suele ser fecha de estreno de procesos creativos que se desarrollaron a lo largo del año. 
Panamá, Paraguay, Perú y Uruguay. Cada uno de estos países realiza un aporte económico anual para la conformación de fondos concursables en distintas líneas de apoyo: creación escénica en residencia, coproducción de espectáculos, y festivales y espacios.

Frente a la retirada del financiamiento por parte del Estado nacional, la posibilidad de acceso a un financiamiento internacional resultó definitoria para llevar adelante el cambio de fecha. La agenda de trabajo para la producción del Festival se ajustó entonces a las posibilidades contempladas en la agenda de Iberescena. Se resolvió que en lugar de realizarse en noviembre de 2017, la quinta edición del Festival tendría lugar en marzo de 2018 y se diseñó una programación -que mantenía el sistema de curaduría a partir de las obras recibidas por convocatoria abiertaacorde a las cuotas de participación internacional previstas por Iberescena. Para el apoyo a Festivales, el Programa Iberescena establecía en la convocatoria 2017 que la programación de los mismos debe estar conformada en un $40 \%$ por artistas provenientes de países miembros del consorcio Iberescena distintos al país sede. A pesar de esto, el financiamiento no les fue otorgado en esa ocasión generando una nueva crisis al interior de la organización del Festival que llevó a pensar en no realizarlo. Finalmente, se resolvió apostar nuevamente al crowdfunding y optar por una programación más acotada y local, que luego pudo ampliarse gracias a la obtención de financiamiento específico para el pago de honorarios a artistas a través del Programa Festejar que consiste en un programa dependiente del Ministerio de Cultura de la Nación que busca fortalecer los festivales culturales sin fines de lucro que se realizan en el territorio nacional argentino. Ofrece asistencia artística (contrataciones y pago de honorarios) y/o escenotécnica (luces, sonido, estructuras de escenario, etc.) para la realización de los festivales y capacitaciones para sus organizadorxs. Otra decisión que se tomó en esta ocasión fue el uso de espacios cerrados dependientes de la Universidad Nacional de La Plata como sede de algunas de las actividades del Festival, que complementaron las actividades desarrolladas en plazas, calles y otros espacios abiertos de la ciudad. La tendencia de definir la programación del Festival una vez que se conocen los resultados de los subsidios solicitados y en función de los recursos concretos con los que se cuenta (en lugar de programar primero y luego buscar los recursos) se fue consolidando a partir de la quinta edición y profundizando en las ediciones siguientes.

Para la sexta edición sí se obtuvo el financiamiento de Iberescena y a éste se sumaron los provenientes del Programa Festejar y del Consejo Provincial de Teatro Independiente (CPTI). Esto permitió ampliar la programación a la vez que aumentar la cuota de artistas internacionales. El vínculo con la Universidad Nacional de La Plata se mantuvo. Destaquemos que el Consejo Provincial de Teatro Independiente (CPTI) es un organismo de la Subsecretaría de Industrias Creativas e Innovación Cultural del Ministerio de Producción Ciencia e Innovación Tecnológica de la Provincia de Buenos Aires, creado con el fin de "fomentar, apoyar y proteger la actividad teatral independiente de la provincia, reconociéndola como un trabajo cultural esencial para el desarrollo integral de la comunidad" (https://www.gba.gob.ar/cultura/cpti). Las funciones del CPTI, así como la porción de la actividad teatral a la que este refiere, son definidas por la Ley provincial 14.037 .

Otra estrategia desarrollada en este último período correspondiente a la quinta y sexta edición, fue la conformación de una Asociación Civil, que nuclea al Centro Cultural Vil Teatro (propiedad de una de las organizadoras del Festival, y sede de varias actividades del mismo) y al festival Danzafuera. Actualmente se encuentran finalizando los trámites fiscales, con vistas a la solicitud de subsidios específicos para este tipo de entidades. 


\begin{tabular}{|c|c|c|c|c|c|}
\hline Edición & Año & Fecha & Duración & Locadiones & Fuentes de financiamiento* \\
\hline $1^{\circ}$ & 2013 & $\begin{array}{l}2 \text { y } 3 \text { de } \\
\text { noviembre }\end{array}$ & $\begin{array}{l}2 \text { dias (un } \\
\text { fin de } \\
\text { semana) }\end{array}$ & $\begin{array}{l}\text { Paseo del bosque y Plaza Islas } \\
\text { Malvinas }\end{array}$ & $\begin{array}{l}\text { Rifas } \\
\text { Fiestas } \\
\text { Auspiciantes }\end{array}$ \\
\hline $2^{2}$ & 2014 & $\begin{array}{l}15 \text { y } 16 \mathrm{de} \\
\text { noviembre }\end{array}$ & $\begin{array}{l}2 \text { dias (un } \\
\text { fia de } \\
\text { semana) }\end{array}$ & $\begin{array}{l}\text { Plaza Belgrano y Parque San } \\
\text { Martía }\end{array}$ & $\begin{array}{l}\text { Rifas } \\
\text { Fiestas } \\
\text { Auspiciantes }\end{array}$ \\
\hline $3^{\circ}$ & 2015 & $\begin{array}{l}26,28 \text { y } 28 \\
\text { de } \\
\text { noviembre }\end{array}$ & $\begin{array}{l}3 \text { dias (un } \\
\text { dla hábil } y \\
\text { un fin de } \\
\text { semana) }\end{array}$ & $\begin{array}{l}\text { Calles céntricas -en dia hábil., } \\
\text { Parque Sarwedra y Parque } \\
\text { Castelli }\end{array}$ & $\begin{array}{l}\text { Fiestas (17\%) } \\
\text { Auspiciantes (13\%) } \\
\text { Financiamiento colectivo (19\%) } \\
\text { Organizacion de seminarios y } \\
\text { talleres (22\%) } \\
\text { Subsidio national -Fondo } \\
\text { Nacional de las Artes- (29\%) }\end{array}$ \\
\hline 4 & 2016 & $\begin{array}{l}3 y 4 \text { de } \\
\text { diciembre }\end{array}$ & $\begin{array}{l}2 \text { dias (un } \\
\text { fin de } \\
\text { semana) }\end{array}$ & $\begin{array}{l}\text { Playbon del Ministerio de } \\
\text { Infraestructura y Servidios } \\
\text { Públicos y Parque Alberti }\end{array}$ & $\begin{array}{l}\text { Fiestas } \\
\text { Auspiciantes } \\
\text { Organización de seminarios y } \\
\text { talleres } \\
\text { Venta de productos } \\
\text { Subsidio nacional Fondo } \\
\text { Nacienal de las Artes- }\end{array}$ \\
\hline $5^{\circ}$ & 2018 & $\begin{array}{l}11 \text { al } 18 \text { de } \\
\text { marzo }\end{array}$ & $\begin{array}{l}9 \text { dias } \\
\text { corridos }\end{array}$ & $\begin{array}{l}\text { Centro de Arte de la UNLP, } \\
\text { ceatros culturales } \\
\text { independientes (Val Teatro, La } \\
\text { Rosa China) Plaza Noreno, } \\
\text { Plaza San Martí, Parque } \\
\text { Savedra, calles céntricas, } \\
\text { Tolosa }\end{array}$ & $\begin{array}{l}\text { Financiamiento colectivo 19\%) } \\
\text { Auspiciantes (3\%) } \\
\text { Subsidio Nacional - Programa } \\
\text { Festejar. (66\%) } \\
\text { Apoyo UNLP (12\%) }\end{array}$ \\
\hline $6^{\circ}$ & 2019 & $\begin{array}{l}9 \text { al } 17 \text { de } \\
\text { marzo }\end{array}$ & $\begin{array}{l}9 \text { dias } \\
\text { corridos }\end{array}$ & $\begin{array}{l}\text { Centro de Arte y Casa de la } \\
\text { Cultura de la UNL.P, centros } \\
\text { culturales independientes (ViI } \\
\text { teatro, La Grieta, El espacio). } \\
\text { centro cultural municipal } \\
\text { (Estación Provincial), calles } \\
\text { de la ciedad }\end{array}$ & $\begin{array}{l}\text { Subsidio internadional } \\
\text {-lberescena-) (71\%), nacional } \\
\text {-Programa Festejar- }(18,5 \%) \text { y } \\
\text { provincial -CPTI- }(9,5 \%) \\
\text { Apoyo UNLP (1\%) }\end{array}$ \\
\hline
\end{tabular}

TABLA 1: Fecha, duración, locación y fuentes de financiamiento del Festival Danzafuera en las sucesivas ediciones.

- Entre partnbesis se indica la contribucisa porceataal de cada fuemte al financiamiento toeal de la correspondiente edicibas del festival (sole para aquellas edicioses en las que se cuenta coe esa isformación).

\section{II}

La organización del Festival implica una serie de actividades y tareas que se desarrollan a lo largo de todo el año y que, aunque estrechamente vinculadas entre sí, pueden ser agrupadas en dos conjuntos: las que se encuentran directamente vinculadas a la organización del Festival y las que apuntan a la consecución de fondos para la producción del Festival, y para que el mismo pueda ser gratuito para el público y pago para lxs artistas.

Dentro de las primeras encontramos las siguientes: definir, redactar y difundir las convocatorias para la recepción de propuestas; recibir las propuestas y realizar la curaduría para la programación del Festival; comunicar los resultados de la curaduría; seleccionar e invitar a lxs coreógrafxs que coordinarán las residencias de creación; redactar la convocatoria para artistas que quieran participar de las residencias, y recibir y evaluar sus postulaciones; coordinar con los equipos de artistas seleccionados; gestionar el alojamiento y alimentación de lxs artistas durante el Festival; seleccionar un artista visual para el desarrollo de la imagen de cada edición; articular con quienes se ocupan del diseño y la comunicación; seleccionar y gestionar los espacios que serán sede del Festival (en el caso de los espacios públicos, esto implica gestionar los permisos municipales necesarios); convocar y coordinar a lxs colaboradorxs; gestionar 
y preparar o pagar el alojamiento y la comida de lxs participantes; coordinar los ensayos generales; resolver los aspectos técnicos (conocer las necesidades para cada propuesta y espacio, conseguir -por préstamo o alquiler- el equipamiento, coordinar con lxs técnicxs encargadxs de cada puesta, etc.); dar notas de prensa; recibir y responder consultas respecto de las distintas convocatorias y de otras cuestiones relativas al Festival; diagramar la distribución en tiempo y espacio de las distintas propuestas que integran la programación; elaborar textos para la comunicación del Festival (texto del programa, para la comunicación en redes sociales, etc); gestionar alianzas e intercambios con distintas instituciones; manejo y elaboración de contenidos para el sitio web y redes sociales; organización del registro audiovisual; coordinación del registro escrito (elaboración, edición y publicación de reseñas).

Entre las tareas vinculadas a la consecución de fondos, encontramos una gran variedad: venta de rifas (que implica elegir y conseguir los premios, vender los números, organizar el sorteo y contactar a lxs ganadorxs); conseguir auspiciantes (para lo cual se requiere previamente de la elaboración de carpetas y de grilla de precios); organizar las fiestas (lo cual implica conseguir y contratar un DJ, elegir y contactar espectáculos que tendrán lugar durante la noche -música y/o danza en vivo, presentador, etc.- y ensayar las coreografías acordes a la temática de la fiesta que lxs mismxs organizadorx bailarán, comprar bebida y hielo, preparar comida para vender, difundir en redes sociales, elaborar la decoración, acondicionar el espacio, atender la barra; cobrar entrada en la puerta, etc); organizar funciones y talleres a beneficio del Festival (para ello es necesario contactar a lxs docentes y artistas, coordinar fechas con ellxs y con la sala en la que tendrá lugar la actividad, articular con diseñadorxs para flyer y otras piezas de difusión, difusión, inscripción, atención de consultas, taquilla en las funciones, preparación de la sala, asistencia técnica de las obras y talleres); realización de campañas de crowdfunding (esto implica la selección de las recompensas y articulación con los diseñadores/artistas que las realizarán, la preparación de la plataforma a través de la cual se realizará la campaña, la difusión de la campaña en redes sociales y otros medios, la realización de notas de prensa, el contacto con cada colaboradxr para la confección de su recompensa -elección de diseño, talle, color, etc-, la articulación con diseñadores y artistas para la elaboración de las recompensas en función de los pedidos efectivamente realizados, la entrega de las recompensas -punto de retiro en el Festival o envíos personalizados, el pago a lxs artistas productores de las recompensas, las gestiones bancarias para el cobro de lo recaudado, etc.); solicitar subsidios (para lo cual es necesario realizar un relevamiento y elaborar una agenda de los subsidios disponibles y acordes a la propuesta del Festival, diseñar estrategias acordes a cada uno, y elaborar los proyectos y carpetas pertinentes en cada caso) y en caso de que sean obtenidos administrar esos fondos (lo cual puede implicar trámites bancarios y fiscales específicos) y luego rendirlos (por medio de la presentación de carpetas con las facturas y comprobantes fiscales de los gastos efectuados y su justificación de uso mediante un informe de desarrollo del evento).

Si bien la separación en estos dos conjuntos puede resultar un tanto arbitraria, ya que las tareas correspondientes a ambos están estrechamente vinculadas entre sí y se afectan unas a otras, la distinción permite visualizar la gran cantidad de trabajo que se dedica a la gestión de recursos económicos. Asimismo, nos permite observar cómo aquellas tareas vinculadas al primer conjunto se han mantenido más o menos estables a lo largo de las distintas ediciones del Festival, en tanto que las del segundo conjunto se han ido modificando considerablemente (se han abandonado algunas e incorporado otras).

Todas estas tareas (las de ambos conjuntos) se discutían, coordinaban y/o realizaban en las reuniones que lxs organizadorxs del Festival sostienen a lo largo del año. Durante las primeras cuatro ediciones, la mayoría de estas reuniones se desarrollaban 
semanalmente en las casas de lxs integrantes del equipo, muchas veces en el horario de la cena que era aquel en el que la mayoría había finalizado el resto de sus actividades. Por este motivo, muchas de las reuniones estaban atravesadas por la preparación de la comida y la cena compartida, y eran de larga duración. Además, la mayoría de las tareas se realizaban entre todxs lxs integrantes del equipo organizador, siendo muy pocas aquellas que se distribuían (la realización de trámites específicos, la redacción de algunos textos puntuales, entre otras). De este modo, en las reuniones se combinaban y articulaban tareas vinculadas a la organización del Festival y a la consecución de fondos.

Para la quinta y sexta edición, las reuniones se realizaron en su mayoría por la tarde, y muchas de ellas tuvieron lugar en bares ubicados en el centro de la ciudad, con lo cual su duración fue más acotada. Su frecuencia se modificaba según el momento del año y las necesidades, no siendo ya un día semanal fijo. La división de tareas fue en aumento, siendo las reuniones principalmente espacios de discusión sobre cómo se llevaría adelante el Festival y no tanto el momento de realización de tareas específicas, que serían luego desarrolladas por las integrantes del equipo. Las tareas que se siguieron realizando en conjunto y presencialmente en las reuniones fueron aquellas vinculadas a la curaduría (selección de lxs coreografxs invitadxs, evaluación y selección de las propuestas recibidas) y a la diagramación en tiempos y espacios de la programación (decisión de las fechas del Festival y sus espacios sede, distribución de las propuestas seleccionadas en esos días y lugares, etc.). Muchas otras decisiones (decisiones respecto de la comida y el alojamiento, por ejemplo), se tomaban a través del grupo de Whatsapp compartido por las organizadoras.

\section{III}

A continuación nos proponemos analizar algunos de los aspectos que hemos narrado sobre la organización y el trabajo del Festival poniéndolos en relación con ideas propuestas por otrxs autorxs que han abordado cuestiones ligadas al trabajo artístico o creativo, y con representaciones sobre el mismo que se pusieron en juego en espacios de encuentro y diálogo dentro del propio Festival, en particular, las mesas de diálogo que se organizaron en las dos últimas ediciones y en las que se invitó a distintxs participantes del Festival a reflexionar sobre las condiciones de producción en las que desarrollaban su actividad. Nos referimos específicamente a la "Mesa de diálogo: El hacer artístico independiente" que tuvo lugar en la quinta edición, y a la "Mesa de diálogo y reflexión ¿Con qué, por qué y contra qué hacemos? Problemáticas comunes al hacer de la cultura y las artes escénicas en el contexto actual", que integró la sexta edición. Desde su quinta edición en 2018, el Festival Danzafuera incluyó en su programación distintos espacios de diálogo entre lxs artistas participantes, invitadxs especiales y el público. A las mencionadas mesas se sumaron otras sobre cuestiones de género en las artes escénicas e historia de la danza local y regional, además de presentaciones de libros con temáticas afines.

Una de las inquietudes que más apareció en estos espacios de charla al interior del Festival, fue la necesidad de deconstruir ciertas ideas sobre el trabajo independiente o autogestivo, en particular, la noción de que producir sin subsidios o apoyos significativos tiene la ventaja de permitir un hacer libre de condicionamientos y que, a fuerza de trabajo y voluntad, cualquier cosa es posible desde la autogestión. Podríamos decir que esta última fue una de las ideas fundamentales en los orígenes y durante los primeros años del Festival: la ilusión de que es posible abrir un nuevo espacio a la medida de los propios deseos, eligiendo sus formas y sus reglas, y que para esto sólo es necesario tener ganas y prepotencia de trabajo. Esta idea, llevó a lxs organizadorxs de las primeras ediciones del Festival a presentarlo de un modo más cercano a lo 
que anhelaban que a lo que podían lograr desde su posición de artistas autogestivxs que apenas se estaban iniciando y contaban con muy pocos respaldos económicos e institucionales. Prometían, por ejemplo, un festival en el que quienes vinieran de una distancia superior a los 100 kilómetros tendrían garantizado el alojamiento y la comida (aunque el alojamiento fuera en las propias casas de lxs organizadorxs y la comida preparada por ellxs mismxs) y el que todxs los participantes podrían cobrar un cachet (aunque fuera simbólico). En las primeras cuatro ediciones, el cachet ofrecido rondó los 73 dólares por obra (de \$500 -pesos argentinos- en 2013 ascendió hasta \$1000 en 2016, actualizado al precio del dólar a la fecha de cada edición, da un promedio aproximado de 73 dólares). Recién a partir del apoyo de financiamientos específicos para honorarios, a través de los programas Festejar e Iberescena, este monto aumentó: en 2018 el cachet para las obras fue de \$5000 (244 dólares) y en 2019 de \$15.000 (356 dólares) Para mayor detalle, ver Tabla 2.

Cumplir con estas promesas sin contar con ningún tipo de subsidio o apoyo institucional y con poca experiencia en la gestión de festivales, requería destinar una gran cantidad de tiempo y esfuerzo a trabajar para conseguir los fondos o recrear las condiciones que permitieran responder a las mismas. Y las estrategias desplegadas para esto (vender rifas, conseguir auspiciantes, organizar fiestas) poco tenían que ver con aquello para lo cual lxs organizadorxs del Festival se habían formado.

Sin embargo, muchas de estas carencias y este esfuerzo parecían matizadas por la idea de estar trabajando entre amigxs, y con la idea de entremezclar el trabajo y el placer. Por ejemplo, que las reuniones fueran cenas con amigxs o que uno de los modos de juntar dinero fuera organizar fiestas para las cuales se fabricaban originales decoraciones o se ensayaban divertidas coreografías.

Por otro lado, el posicionamiento en lo independiente parecía la mejor posibilidad para mantener la libertad creativa y poder decidir plenamente y sin condicionamientos qué tipo de festival se quería generar. Las representaciones en torno al concepto de independencia en el campo de la danza contemporánea de la ciudad de La Plata han sido analizados previamente en Sáez $(2015,2016)$. Si bien la mayor parte de lxs integrantxs del equipo organizador veían como deseable la obtención de un apoyo por parte del Estado (e incluso fantaseaban con la idea de que en un futuro, el Festival fuera impulsado por la municipalidad) existían, al interior del equipo, algunas resistencias a esta idea que daban lugar a discusiones sobre la posibilidad de producir sin ningún tipo de condicionamientos. Algunxs de lxs integrantes consideraban, por ejemplo, que era preferible un mecenazgo privado que trabajar con el sello de un gobierno con cuya orientación política podía o no estarse de acuerdo. También consideraban que la introducción del Estado en la gestión del Festival podía llegar a transformarse en un condicionante que desviara al mismo de aquello que habían imaginado.

Sin embargo, con el pasar de los años, algunas de las ideas sobre la independencia y la autogestión que habían orientado muchas de las decisiones y las estrategias que dieron lugar a las primeras ediciones del Festival comenzaron a entrar en crisis. La distancia entre el festival deseado y el efectivamente posible y realizado, comenzó a hacerse visible en distintos aspectos. Así como la vinculación con el Estado se consideraba que conllevaría ciertas restricciones para la realización del Festival, empezó a evidenciarse que las condiciones de producción independientes también lo hacían. La decisión de qué obras se programaban, y cuáles no, no dependía únicamente de una valoración estética: cuántas personas había que alojar y alimentar, si era posible o no ofrecer una ayuda para los traslados, cuál sería el monto del cachet y si los propios artistas aceptaban o no participar del Festival en esos términos, eran factores que influían en las decisiones y en la conformación final de la programación de cada edición. 
La evidencia de estos condicionantes, sumada a la experiencia de las sucesivas ediciones, puso de manifiesto que el festival deseado era un festival de alto presupuesto. Implicaba que lxs artistas cobraran por su trabajo y que el público no pagara; que la programación fuera amplia y diversa y que incluyera propuestas internacionales; que se ofreciera alimentación, alojamiento y viáticos para lxs participantes; etc. Producir un festival de estas características desde la autogestión implica mucho trabajo en pos de la consecución de los recursos necesarios.

Con el paso del tiempo, dentro del grupo de organizadores, empezó a haber un cuestionamiento cada vez mayor de las actividades que realizaban para poder gestionar fondos. La organización de fiestas, la venta de rifas y la búsqueda de auspiciantes empezaron a visibilizarse como trabajos en los que se invertía mucho tiempo, para los cuales no estaban formadxs, y que no siempre eran tan redituables. De a poco, esas actividades comenzaron a menguar, y aparecieron otras estrategias de financiamiento más ligadas a la formación propia del grupo. De este modo, empezaron a enfocarse en pedir subsidios y nació Danzadentro (ciclo de funciones y seminarios de danza donde las ganancias servían para financiar el Festival).

Unos años más tarde, el trabajo implicado en la organización de eventos como Danzadentro se evaluó como excesivo en relación con las ganancias económicas que dejaba para la organización del Festival y las estrategias se enfocaron cada vez más fuertemente en la obtención de subsidios. El cambio en la fecha del Festival, determinado en gran medida para favorecer el pedido de financiamiento a Iberescena es un claro ejemplo de esto. El vínculo con la Universidad Nacional de La Plata fue también parte de estas estrategias. El uso de espacios que cuentan con infraestructura y personal propio resultaba un alivio tanto en términos presupuestarios como de trabajo del equipo organizador. Esto puede apreciarse en la Tabla 2, en la que se observa para la quinta edición un aumento considerable en el porcentaje del presupuesto total que es destinado a honorarios artísticos. Si bien esto responde en buena medida al apoyo del Programa Festejar -que fue obtenido a último momento y permitió mejorar considerablemente el monto del cachet de lxs artistas-, también se vincula con que el Centro de Arte de la Universidad Nacional de La Plata haya sido entonces la principal sede el festival, aliviando a la organización del mismo de otros gastos (alquiler de luces y sonido, honorarios técnicos, entre otros).

La decisión de enfocarse en estas estrategias traía consigo sus propios condicionantes (fechas preferibles, características de los espacios, proporción de obras internacionales, etcétera), pero fueron evaluados como menos restrictivos y/o menos autoexplotadores o autoprecarizantes que aquellos provenientes de las estrategias previamente desarrolladas.

Al mismo tiempo, no sólo dentro del grupo organizativo, sino también dentro de la comunidad de la danza platense, comenzaron a volverse más visibles algunas de las facetas más negativas del trabajo autogestivo, volviéndose cada vez más frecuentes términos como autoexplotación y precarización para referir al propio quehacer y, habituales, las referencias a cómo lo independiente también genera restricciones.

\section{IV}

Las nociones de autoexplotación y autoprecarización, así como otras ideas que alertan sobre los vínculos y similitudes entre el trabajo artístico y los mecanismos del capitalismo contemporáneo, fueron desarrolladas por autoras como Isabell Lorey y Bojana Kunst quienes, en diálogo con la propuesta de Luc Bolstanski y Eve Chiapello en $E l$ nuevo espíritu del capitalismo (1999), resaltaron la autonomía, la autorrealización, la 
creatividad y la desaparición de la diferencia entre tiempo de trabajo y tiempo privado como características del trabajo creativo contemporáneo, que se han convertido en aspectos centrales dentro de las estrategias del capitalismo posindustrial.

En sintonía con estas ideas, Lorey (2006) refiere al modo en que los productores y productoras culturales llevan a cabo una precarización elegida para sí contribuyendo de ese modo a producir las condiciones que permiten convertirse en parte activa de las relaciones políticas y económicas neoliberales. La autora sitúa los inicios de esta precarización elegida en los movimientos de los años sesenta en los que se buscan modos alternativos de vida como formas de resistencia. Plantea que estas prácticas

se orientaban de forma persistente a diferenciarse de las condiciones de trabajo normales y a distanciarse de las coacciones, medidas disciplinarias y controles que a éstas se asociaban. Sus palabras clave eran: decidir por sí mismo en qué trabajar y con quién; elegir formas precarias de trabajo y vida en tanto y en cuanto parecía posible una mayor libertad y autonomía, precisamente a partir de la organización del tiempo propio; y lo más importante de todo, autodeterminación. Con frecuencia, estar bien pagado o bien pagada no era una preocupación, porque la remuneración consistía en disfrutar del trabajo. Lo que preocupaba era poder desarrollar las capacidades propias. Por lo general, la aceptación consciente y voluntaria de condiciones de trabajo precarias venía a ser una expresión del deseo de vivir la separación moderna y patriarcal entre reproducción y trabajo asalariado de una manera diferente a la que permitía la situación de trabajo normal (Lorey: 2006: 11).

Sin embargo, tal como señala Lorey, "son precisamente estas condiciones de vida y trabajo alternativas las que se han convertido, de forma creciente, en las más útiles en términos económicos, puesto que favorecen la flexibilidad que exige el mercado de trabajo" (íbidem), de modo tal que no sólo no han logrado oponerse a la normalización, sino que se han vuelto parte de los mecanismos centrales de la gubernamentalidad neoliberal.

También en línea con estas propuestas, la filósofa y dramaturga eslovena Bojana Kunst publicó a mediados de esta década trabajos (2015a y b) en los que retoma y profundiza estas ideas. Se propone mostrar que, en la sociedad contemporánea, el artista se ha convertido en un prototipo de trabajador flexible y precario, debido a que su trabajo muchas veces voluntario o mal pago requiere de una disponibilidad permanente que diluye la distinción entre tiempo libre y tiempo laboral. Plantea, así, que la desaparición de las fronteras entre arte y vida que muchxs artistas del siglo XX situaron en el centro de sus tendencias emancipatorias, se encuentran hoy en día en el centro de la producción capitalista de valor. De este modo, todo aquello que en principio es visto como liberador, resulta tener un efecto devastador sobre la vida de los sujetos, una vida marcada por una incesante actividad que los lleva "de un trabajo a otro, de un compromiso político y laboral a otro" de modo tal que su vida laboral desborda todas las otras dimensiones de su existencia y la buscada libertad se transforma en "dependencia cotidiana a un sinfín de tareas y proyectos" (Kunst, 2015b: 163).

Todo esto genera, según la autora, un "omnipresente sentimiento de precariedad" que resulta constitutivo del entorno afectivo en el que habitan los artistas, un sentimiento basado en "una frustración y un libre disfrute simultáneos" (Kunst, 2015b: 158) y en relación al cual se desarrollan redes de solidaridad y amistad para poder paliar dicha precariedad e inestabilidad. De este modo, el aura social que rodea al arte, los vínculos de amistad entre quienes lo realizan y el valor de vida artística en general ocuparían un rol central en los mecanismos del capitalismo postfordista para la explotación de la vida y la producción de valor. 
La descripción realizada por estas autoras se ajusta en múltiples puntos a lo ocurrido en el caso que venimos narrando (así como en las historias de la gran mayoría de quienes trabajan en el ámbito del arte y la cultura en La Plata). En primer lugar, la sensación de potencia y autorrealización por estar generando, por pura determinación, deseo y fuerza de trabajo, un nuevo espacio de encuentro y visibilización de la danza, coincide con la descripción realizada por Lorey de las condiciones que darían lugar a una precarización elegida. Al mismo tiempo, el borramiento de la línea divisoria entre trabajo y ocio se ponía de manifiesto en las reuniones, que eran por lo general cenas entre amigxs, en las que preparar la comida, cuidar al bebé de una de las compañeras de equipo, contarse los sucesos del día o hacerle masajes a un compañero contracturado eran quehaceres que se mezclaban con las tareas específicas de la organización del Festival y la consecución de fondos para realizarlo. Lo mismo ocurría con la organización de las fiestas, que fueron una importante fuente de financiamiento durante las primeras ediciones. Además de la gestión del espacio, la contratación de un DJ, la compra de bebida y la difusión del evento (tareas habituales en la organización de cualquier evento de ese tipo) Danzafuera solía personalizar sus fiestas con dos recursos que implicaban un conjunto de tareas extra para el equipo: una decoración temática del espacio fabricada e implementada por ellxs mismxs y un pequeño número de baile, en el que lxs organizadores interpretaban una serie de éxitos musicales comerciales en un tono levemente paródico. Ambas propuestas implicaban un nuevo abanico de tareas que, si bien resultaban sumamente entretenidas, sumaban una importante cantidad de horas de ensayo y/o reunión, que en las sobrecargadas agendas de lxs miembros del equipo, solían encontrar lugar sólo en las madrugadas o fines de semana.

Si bien la sensación de estar trabajando entre amigxs, en un contexto relajado y divertido, contribuyó en numerosas ocasiones a invisibilizar las enormes cantidades de tiempo y trabajo invertidas, y el carácter sumamente precario del mismo, en más de una ocasión, el cansancio de estar ensayando una coreografía un domingo a la mañana o fabricando una nube de papel maché un lunes a las 3 de la madrugada ponía en evidencia el sinsentido de esa actividad y abría grietas que invitaban a repensar las estrategias puestas en juego. Todo este panorama, llevaba a que el sentimiento predominante fuera, tal como lo describe Kunst, el de "una frustración y un libre disfrute simultáneos" en el que la sensación de un hacer elegido, placentero y divertido se mezcla con la percepción del carácter autoprecarizante de la tarea realizada.

Con el pasar del tiempo, nociones como las de autoprecarización y autoexplotación empezaron a estar cada vez más presentes en las charlas y discusiones no sólo de lxs organizadorxs de Danzafuera, sino también en gran parte de la comunidad de la danza local. Sin embargo, la puesta a la luz de estos mecanismos, no trazaba necesariamente un camino a seguir. En un contexto como el platense, en el que la vía autogestiva se presenta casi como la única forma de producción posible. Señalemos que esta característica de la producción escénica de la ciudad de La Plata es analizada en trabajos previos. Para profundizar en esta cuestión sugerimos la lectura de los artículos de del Mármol, Magri y Sáez (2017), Basanta y del Mármol (2017))¿Cuál podría ser, entonces, la alternativa?

\section{V}

En su trabajo Artist at work, Bojana Kunst (2015a) reflexiona sobre las características del trabajo artístico, para mostrar cómo el arte se acerca al capitalismo y, al mismo tiempo, se resiste a la apropiación capitalista de su potencia creativa. En las páginas finales de este texto, refiere a ciertos argumentos sobre el arte y su productividad que deberían ser pensados de manera desobediente para que lxs artistas puedan resistir a la explotación de su poder creativo. 
La primera de estas desobediencias tiene que ver con la relación entre el arte y la economía: la autora propone que más que señalar que las artes forman una parte importante de la economía contemporánea y de las industrias creativas, generando un importante valor económico, debe evidenciarse que el arte no está conectado a la economía de la producción de valor, sino que está, por el contrario, mucho más cerca del gasto sin objetivo.

La segunda desobediencia se refiere a la utilidad y la naturaleza productiva del trabajo del artista. Plantea que en un momento en el que numerosos tipos de trabajo y actividades (no solo artísticas) se vuelven inútiles e innecesarias, exigiendo actualizaciones constantes en pos de demostrar la capacidad de adecuarse a las nuevas necesidades del mercado laboral y la productividad del propio quehacer, evidenciar los errores, la pasividad y la pereza (recursos que se encuentran presentes en muchas obras de arte contemporáneo) se constituyen, también, en un gesto de resistencia.

En tercer lugar, discute con la idea de Hannah Arendt de que el trabajo artístico constituye una excepción respecto de otros trabajos, ya que no se encuentra relacionado "con la materialidad de la vida y la minuciosa conservación de la naturaleza" (Kunst, 2015:189, la traducción nos corresponde). Kunst plantea que, en la actualidad, el quehacer artístico no es excepcional, porque está subordinado a la necesidad de trabajo; es decir, se trata cada vez más de trabajar y menos de crear. Aunque preserva esta excepcionalidad en el imaginario social, resulta el tipo de trabajo que más fusionado se encuentra con la vida y cuyo nivel de dedicación e intensidad menos espacio deja para la vida.

Sin embargo -continúa argumentando la autora- la cercanía del trabajo artístico al capitalismo es ambivalente: si bien ya no es excepcional y constituye un modelo sobre el modo de aprovechar al máximo la capacidad creativa que resulta paradigmático para el modo de producción del capitalismo actual, al mismo tiempo, mantiene vínculos con los procesos materiales y encarnados de la creación que eluden la necesidad de la vida.

De este modo, existiría una posibilidad de resistencia en la "conciencia de la potencialidad no realizada de los poderes creativos" (Kunst, 2015:192). La distancia crítica entre el arte y los modos de producción requeridos por el capitalismo actual podría entonces radicar en la posibilidad de trabajar menos. En palabras de la autora:

Hacer menos también habla de una actitud específica por parte del trabajador artístico, que necesita soportar las especulaciones creativas sobre su vida para abrir la materialidad temporal de su propio trabajo. De esta manera, el trabajo del artista cede a la vida, no en el sentido de romper los límites entre la vida y la actividad artística, sino siempre en el sentido de colocar su actividad como la diferencia autónoma de un acto menor: es permitir la vida haciendo menos. En este sentido, hacer menos puede entenderse como un cambio afectivo excepcionalmente importante que puede influir significativamente en los ambientes rítmicos y flexibles de la vida artística contemporánea y abrir nuevas formas de solidaridad. Esta sería entonces la tercera línea de desobediencia en la defensa del arte: hacer menos, precisamente cuando se enfrenta a la demanda de hacer más (Kunst, 2015:193 [La traducción es nuestra]).

En sintonía con estas ideas, en las Mesas de Diálogo organizadas por Danzafuera en sus dos últimas ediciones, la necesidad de detenerse, elegir más y hasta dejar de hacer aparecieron en numerosas oportunidades. 
En el primero de estos encuentros, la necesidad de hacer menos emergió como la medida primordial contra la sobreocupación característica de lxs artistas que producen de modo autogestivo. Se habló de la necesidad de cuestionar la idea de que "en lo independiente todo es posible", evidenciando los costos (en términos de cantidad y calidad de tareas realizadas, agotamiento físico y emocional y, en ciertos casos, endeudamiento económico) que genera el imaginario de que es posible sumarse a infinitos proyectos y que una actitud de entrega absoluta hará posible la realización de empresas de cualquier magnitud. En relación con esto se planteó la necesidad de hacer menos, elegir en qué espacios y con quiénes trabajar (y en cuáles no); sin embargo, hubo un acuerdo generalizado en que no era una opción dejar de hacer.

Transcribimos a continuación un fragmento del texto que envió uno de lxs participantes de este encuentro como parte del intercambio que se dio por e-mail en los días previos al mismo:

De una manera súper fraccionada genero mi sostén económico desde las actividades que realizo desde la danza (obra, gestión, docencia; trabajo de esto, me dedico, vivo de-por-para esto), estoy super agradecido por ello, pero la relación trabajo-horas-remuneración económica no siempre condice con este vínculo en otros campos laborales.

Si trabajáramos sólo cuando estas condiciones son coherentes con el costo de vida hoy, poco haríamos y pocos accederían a hacer. De todas maneras, dejar de hacer claramente no nos representa una opción. Seguir haciendo aquello en lo creemos nos urge, nos moviliza, nos acerca.

\section{(...)}

Pareciera que la autoexplotación es característica indisociable de lo independiente, volviéndonos funcionales a la figura en emprendedurismo.

Seguir en un hacer que cuestione este vaciamiento. Abonar los encuentros como generadores de políticas contestatarias. Tejer redes que destruyan el binomio centro periferia.... ¿Qué hacer? ¿Que dejar de hacer?

El término auto-explotación estuvo muy presente en este encuentro porque las organizadoras del Festival lo habían utilizado en el texto editorial que publicaron en el programa de mano que entregaban en las distintas actividades del evento. En este texto, mencionaban la gran cantidad de trabajo y recursos que requería la realización de un festival de tal magnitud y la contradicción que les generaba sostener la premisa de que el Festival siga siendo gratuito para el público y brinde un pago a lxs artistas, y agregaban:

En general llegamos a cubrir los cachet para Ixs artistas, pero nuestro trabajo, el de Ixs tecnicxs y el de lxs colaboradorxs no es remunerado. Cada año intentamos revertir esta situación, pero aún no le encontramos la vuelta. A esta altura creemos que somos portadoras de una utopía. Una utopía que obviamente nos da una satisfacción personal inmensa pero a cambio de nuestra auto-explotación.

El texto terminaba refiriendo al valor del Festival como lugar de encuentro y construcción colectiva, y la necesidad de este tipo de espacios en momentos de crisis económica en que la búsqueda de salidas individuales puede atentar contra el hacer compartido y reafirmando la decisión de organizar una nueva edición del Festival a pesar de no contar con los apoyos esperados. Recordemos que previamente a 
esta edición hubo una situación de crisis que llevó a una reformulación de varios aspectos de la organización del Festival (como el momento del año y los espacios en los que se realizaba) en función de la posibilidad de obtener subsidios o aprovechar recursos existentes y que por única vez se consideró la posibilidad de no realizar el Festival o reducir considerablemente su magnitud para ajustarse a los recursos disponibles.

Nos pareció interesante compartir estos fragmentos de textos porque muestran, por un lado, una ruptura con la mirada ingenua que se aferra sólo a la potencia del hacer autogestivo invisibilizando sus costos y, por otro lado, cómo a pesar de que la idea de hacer menos o detenerse y elegir qué hacer aparece como necesaria para no caer de forma irreflexiva en la autoexplotación (o, como se mencionó en una de las mesas de diálogo, volverse funcionales al discurso del emprendedurismo). En ninguno de los casos parece ser una opción dejar de hacer.

Pareciera entonces que en el contexto que se autodenomina como independiente o autogestivo, la opción de hacer menos o dejar de hacer sólo puede interpretarse de manera parcial: dejar de hacer algunas cosas (como vender rifas u organizar fiestas) o dejar de aceptar participar en todos los proyectos, pero en ninguno de los casos parece reflejarse en un trabajarmenos y mucho menos en un hacer más perezoso.

Podríamos pensar que la opción de evidenciar la pereza o el detenerse es una opción más factible de llevar a cabo en una obra (como la del croata Mladen Stilinović a la que refiere Kunst) que en un proyecto centrado en la gestión como es la organización de un festival. Incluso, una de las propuestas que tuvo lugar en la quinta edición de Danzafuera (un recorrido a cargo de las integrantes del proyecto Territorio Tolosa) incluía la lectura de un manifiesto sobre la necesidad de (re)parar, que podría pensarse como una acción en este sentido. Transcribimos aquí algunos fragmentos:

\section{LO QUE HAY QUE HACER ES PARAR DE HACER}

(...) HAY QUE PARAR

Para VER, hay que detenerse o andar más despacio, caminar.

(...)

hay que inventar una excusa para salir y hacer algo tan improductivo como charlar. Hacer algo que no le sirve a nadie es muy difícil de instalar, tiene muy poca prensa. Así que...

DES-INS-TA-LÉ-MO-NOS

No hay más tiempo para hacer, estamos todos haciendo

No hay más tiempo para ver imágenes, estamos todos subiendo fotos a Instagram No hay más tiempo para leer, estamos todos escribiendo nuestras autobiografías, actuando,

pidiendo algo, poniendo me gusta. Ya no hay espectadores. Estamos todos haciendo.

HAY QUE PARAR

HAY QUE PARAR

reflexionar, y pensar juntos, y ver lo que está afuera.

TODO PARO ES POLITICO me dijeron y esto es un paro y es político

(...)

Basta de construir sin parar

Basta de demoler sin parar

Basta de trabajar sin parar

DES-INS-TA-LÉ-MO-NOS 
El texto anteriormente citado fue redactado por Luciana Lima (bajo la supervisión de Magda de Santo) en el marco de las investigaciones-reflexiones-caminatas realizadas con el colectivo Territorio Tolosa - Proyecto Beca de Arquitectura a la Creación Fondo Nacional de las Artes. Se repartió impreso a los participantes y fue leído colectivamente en el cierre del recorrido que Territorio Tolosa propuso en el marco de la quinta edición de Danzafuera.

Este manifiesto tiene numerosos vínculos con la propuesta de Kunst, con la denuncia y la llamada a una ruptura con la lógica de producción y la temporalidad propia del capitalismo. Sin embargo, más allá de lo que sucede en el tiempo de los recorridos que propone el proyecto Territorio Tolosa, ¿cuánto del contenido de este manifiesto se refleja en los modos de trabajo de quienes participan en el mismo? ¿El quehacer de qué artista permite parar? ¿En qué contextos?

Algunas de estas preguntas aparecieron en la charla de la edición 2019, en la que la idea de dejar de hacer tomó dos formas diferentes. Por un lado, una de las coreógrafas participantes, vinculó el hacer (y el dejar de hacer) con una responsabilidad política poniendo sobre la mesa la pregunta “¿Cómo sería tu mundo si no hicieras lo que hacés en relación al arte?”. Así, desde esta pregunta contrafáctica, invitaba a pensar las consecuencias del dejar de hacer. "La pensé porque me pareció que nos permitía discutir acerca de la relación entre deseo, la falta del deseo o su disminución, responsabilidad, hábito, expectativa tanto individual como colectiva respecto del estado de las cosas en nuestra práctica de la danza". Esta argumentación, así como la pregunta de la cual se desprende, fueron aportadas por Diana Rogovsky, bailarina, coreógrafa, docente y gestora cultural de la ciudad de La Plata, como parte del intercambio realizado por e-mail en los días previos a la Mesa de diálogo y reflexión “¿Por qué, con qué y contra qué hacemos?" realizada en el marco del Festival Danzafuera en el año 2019.

A la idea de parar y de dejar de hacer, se opuso entonces la militancia y la responsabilidad para con otrxs. Siguiendo esta misma línea de razonamiento, la misma coreógrafa señaló que el Festival cumplía un importante rol en la comunidad de las artes escénicas al producir política cultural y al generar, gestionar o redistribuir recursos entre lxs artistas en un contexto en el que el Estado no tenía políticas similares. En esta misma línea se refirió al trabajo de la ACIADIP y otras agrupaciones, que se sostienen como una militancia colectiva que busca transformar el estado de situación. Así, dejar de hacer en estos contextos, implicaría dejar de sostener espacios que intentan promover mejores condiciones para la vida y para la producción artística de la comunidad.

Respecto de la idea de Kunst sobre la necesidad de ir en contra del argumento que señala la importancia del valor económico generado por las artes para la economía contemporánea y las industrias creativas y su propuesta de enfatizar la desconexión del arte de la economía de la producción de valor y su cercanía al gasto improductivo, nos preguntamos ¿cómo se articula esta idea con la militancia por la reivindicación del arte como trabajo en la que tantos artistas e intelectuales vienen trabajando? ¿Qué fuerza de resistencia tiene cada una de estas posiciones? ¿Qué aspectos de cada una de estas ideas resultan más útiles para la descripción de las condiciones de producción de lxs artistas y gestorxs de la ciudad de La Plata?

Podríamos decir que ambos argumentos conviven o son necesarios para explicar el tipo de economía que sostiene a Danzafuera. El equipo que impulsa el Festival intenta ( $\mathrm{y}$ ha intentando desde sus inicios) movilizar recursos económicos que permitan generar puestos de trabajo para lxs artistas participantes y un evento cultural abierto y gratuito que coloque a la danza en los espacios públicos de la ciudad. La militancia por parte de lxs organizadorxs por reconocer la participación de las compañías seleccionadas y artistas invitadxs en términos de trabajo, mediante el pago 
de un cachet (que en varias ocasiones resultaba tan bajo que se consideraba un pago simbólico) implicó, contradictoriamente, incrementar de manera notoria sus horas de trabajo impago. Incluso en la última edición -que mediante el cobro de subsidios de Iberescena, Festejar y CPTI fue la que más recursos movilizó-, las sumas recibidas por varixs de los participantes se mantuvieron en la categoría de pago simbólico y el dinero recibido por las organizadoras por única vez (apenas equiparable al salario -bastante magro- de un mes) resulta sumamente escaso para las horas de trabajo invertidas durante todo un año y mucho más si se consideran los años anteriores en los que no recibieron remuneración alguna.

Mientras tanto, en todas las ediciones, una parte importante de los recursos obtenidos circula hacia afuera del ámbito de la danza (con el pago del diseño o la ilustración, por ejemplo) e incluso del ámbito del arte (con el pago del alojamiento y comida, o los gastos de imprenta y publicidad). Pero aun considerando estos otros gastos y a lxs destinatarixs (artistas o no) de estos recursos, el dinero obtenido, aunque para las sumas que estamos acostumbradxs a manejar individualmente parece una suma muy significativa, no lo es tanto si se considera la cantidad de personas que intervienen en el Festival y la cantidad de horas de trabajo invertidas en la organización del mismo.

Desde la lógica de la contabilidad, si promediáramos el dinero recibido (no sólo por las organizadoras, sino también por la gran mayoría de lxs artistas participantes) en función de las horas de trabajo invertidas (y en muchos casos el dinero utilizado), los resultados nos hablarían de pérdidas más que de ganancias y en este sentido, parece coincidir con aquello que Georges Bataille (1987 [1933]) conceptualiza en términos de "gasto improductivo", la noción en la que Bojana Kunst ancla su argumento. Se trata de actividades en las que -en palabras de Bataille- "el énfasis se sitúa en la pérdida, la cual debe ser lo más grande posible para que adquiera su verdadero sentido" (28), de modo que se guían por una lógica contraria al principio económico de la contabilidad en el que el gasto debe ser compensado por la adquisición.

Siguiendo el argumento de Kunst podríamos pensar a Danzafuera como una fiesta -y de hecho en el texto editorial que acompañó el programa de mano en la edición 2014 el Festival se definía de ese modo $^{2}$-, como un espacio en el que se gasta de manera improductiva un gran cúmulo de recursos. Un evento social y público en el que las organizadoras y los participantes ofrecen lo conseguido después de un año (e incluso de varios años) de trabajo para el disfrute y el encuentro colectivo. En cierta medida los efectos y el lugar que ocupa Danzafuera en la comunidad de la danza platense cuadran con esta descripción. Esto puede observarse también en las descripciones del Festival que han quedado plasmadas en los fanzines que el mismo organizó en sus ediciones 2018 (Sáez y López Betancourth, 2018) y 2019 (del Mármol y Sáez, 2020), en los cuales se reúnen una serie de textos producidos en el marco del Festival a modo de reseña de las diferentes actividades que comprenden cada edición.

Sin embargo, incluso cuando esta interpretación se adecúa en gran medida al modo en que el Festival es vivenciado tanto por sus organizadoras como por la comunidad de la danza que se reúne en torno a este espacio y nos permite completar la explicación de un panorama económico sumamente complejo ¿se trata realmente de un funcionamiento económico alternativo? ¿Son en verdad opuestas las dos lógicas

2 Transcribimos a continuación algunos fragmentos de ese texto editorial: "Sabíamos que un festival es una fiesta y la danza necesitaba (y necesita) más fiestas, encuentros entre pares y nuevos lugares de encuentro con el público. (...) Esperamos que el festival se modifique y crezca según las necesidades de todos. Que siga siendo fiesta, lugar de encuentro, de reflexión, de nuevo pensamiento, que cada vez pueda albergar de todas formas a más cantidad de interesados, artistas y espectadores; que los públicos se mezclen, se pregunten, se bailen. Por ello lo llevamos a cabo, lo creamos, porque primero lo soñamos, porque nos hubiera gustado que exista siempre y porque esperamos que se mantenga en el tiempo, y que cada año la fiesta sea mayor". 
o interpretaciones que hemos expuesto? Incluso cuando los recursos monetarios obtenidos son escasos y el gasto de tiempo y dinero adquiere grandes dimensiones ¿no hay otras ganancias en juego? ¿Y no conforman estas otras ganancias un sistema económico que se articula e influye en las ganancias monetarias que tienen o podrían obtener sus beneficiarixs?

¿Qué ocurre con esas otras ganancias que se adquieren en términos de legitimación y visibilidad no sólo para las organizadoras sino también para todxs lxs participantes? ¿No configura esta otra moneda de cambio un sistema de intercambio y circulación que se encuentra moldeado por las lógicas de producción capitalistas y se integra de modos diversos a las mismas? Sobre el modo en que el reconocimiento y la legitimación funcionan en el ámbito teatral platense como moneda de pago quedando subsumidas a una lógica mercantilista del tipo de aquella que habitualmente se intenta evitar, remitimos a Basanta y del Mármol (2018).

\section{VI}

Sin dudas el reconocimiento es una moneda de pago muy importante, incluso la principal en este tipo de circuitos que coinciden con lo que Bourdieu definió como el campo de producción restringida de bienes simbólicos (2003 [1971]).

Que este sea el principal capital en juego dentro de dicho campo explica en gran medida que sus organizadoras manifiesten que lo que más les interesa sea el placer que les reporta la posibilidad de concretar la realización del Festival y el prestigio que el mismo les confiere dentro del campo, haciendo que la retribución monetaria quede en segundo plano. La internalización de esa lógica en la que el reconocimiento vale más que el dinero explicaría por qué el dejar de hacer no puede ser más que parcial o simbólico. Por qué aparece en los discursos la afirmación de que más allá del registro de la autoexplotación dejar de hacer no es una posibilidad. Implicaría desaparecer.

Podríamos incluso pensar que esta lógica funciona como una ideología en tanto no sólo ofrece una explicación del modo en que se producen y circulan los bienes simbólicos, sino que también lo justifica y perpetúa. Este uso de la noción de ideología es propuesto por la antropóloga franco-estadounidense Anne Chapman (1986), en su trabajo sobre los pueblos Selk nam de Tierra del Fuego.

Autoras como Mauro (2018) o Baranchuk (2016) han enfatizado los modos en los que el capital logra producir valor a partir de la cultura señalando la existencia de una plusvalía que se genera a partir del trabajo artístico pero que es apropiada por otros actores y sectores (como los empresarios de los circuitos comerciales y los medios masivos de comunicación, y el Estado que se beneficia al ampliar su oferta cultural). Si bien estas investigaciones dan cuenta de un panorama que no coincide completamente con el platense, consideramos que las preguntas que allí plantean resultan igualmente pertinentes y relevantes en este caso.

En este sentido, abrimos una mirada crítica sobre la lógica imperante en el circuito que nos encontramos describiendo, y volvemos a indagar -a pesar o en contra de lo sugerido por Kunst (2015)- en la producción de valor económico que se da dentro del mismo, cabe preguntarnos si Danzafuera produce únicamente capital simbólico o si por el contrario hay también producción de valor económico y, en este último caso, cuáles son los sectores que se benefician del mismo.

Como hemos visto sí hay otros sectores (alojamiento, comida, diseño) hacia los que ha circulado una parte importante del dinero movilizado por Danzafuera. 
Sin embargo, también podríamos pensar en un dinero que Danzafuera no ve o no maneja directamente, pero que sabe que existe de manera virtual o potencial. El vínculo con la Universidad Nacional de La Plata es un ejemplo de esto. La UNLP contribuye con el Festival posibilitando el uso de sus instalaciones para diversas actividades y hace además una pequeña colaboración económica con el evento (10.000 y 5.000 pesos, en 2018 y 2019 respectivamente. Como puede observarse en la Tabla 2, estos montos representan una cifra "pequeña" en comparación con el presupuesto total del Festival en esas ediciones, y con lo obtenido de otras instituciones, en particular en la edición 2019). Esta colaboración es más o menos equivalente al pago que la misma institución realiza a las obras que se programan en su sala, pero en el caso de Danzafuera implica la realización de una cantidad mayor de obras y otras actividades (cinco obras, dostalleres y una presentación de libros en 2018; dos obras, tres talleres y dos charlas en 2019). En este sentido, si evaluamos los recursos que la UNLP debería haber invertido para gestionar una programación semejante, hay un ahorro de dinero por parte de la gestión estatal que Danzafuera no percibió por el trabajo realizado. Además, por supuesto, del ahorro de trabajo (ya que la gestión de estas actividades se realiza íntegramente por el equipo organizador del Festival) y de la apropiación de capital simbólico que también Danzafuera aporta a la UNLP al programarle diversas actividades con alcance internacional.

La Municipalidad de La Plata puede ser otro ejemplo de esto último. En la sexta edición del Festival, dos de las obras se presentaron en una zona verde en torno a un centro cultural de gestión municipal. A cambio del uso de ese espacio, las organizadoras debieron incluir el logo del municipio en el programa de mano del Festival, lo que generó discusiones y resistencias entre las organizadoras respecto de la utilización del capital simbólico generado por el Festival por la intendencia.

Volviendo al argumento de la producción de valor económico y su apropiación diferencial, además de la apropiación por parte de las instituciones estatales, es interesante observar entre qué otros agentes se distribuye y en qué medida.

En la tercera edición, el Festival movilizó \$30.000 de los cuales la mitad se destinó a honorarios de los artistas. El otro 50\% se destinó al pago de comidas, diseño, impresión de folletería, comunicación y a la compra de los productos que se ofrecieron como recompensas en la campaña de crowdfunding. En la quinta edición, el monto invertido en estos rubros fue de $\$ 23.000$ en tanto que $\$ 60.000$ se destinaron al pago de honorarios de lxs artistas, representando un $28 \%$ y un $72 \%$ respectivamente.

En la última edición, el Festival movilizó 423.000 pesos. El incremento en el monto disponible para este Festival se debió, como mencionamos anteriormente, al otorgamiento de un subsidio por parte de Iberescena. Cabe, no obstante, mencionar que se trató de un financiamiento parcial de 7000 euros (equivalente a unos \$200.000 al momento de su otorgamiento en diciembre de 2018), cuando el monto máximo otorgado para la realización de festivales es de 35.000 euros. Los honorarios de los artistas participantes sumaron $\$ 148.000$, un $35 \%$ del total. Los honorarios del equipo organizador totalizaron $\$ 80.000$, es decir, un $19 \%$. Sumando ambos montos, el total destinado a honorarios artísticos se ubica en el 54\%. El porcentaje restante se destinó a alojamiento, comida, diseño de la imagen del festival, impresión de folletería, servicios de prensa y comunicación, pago a técnicxs y colaboradorxs, registro audiovisual y fotográfico y alquiler de sala (para una única obra). 


\begin{tabular}{|c|c|c|c|c|c|}
\hline Edición & Ano & $\begin{array}{l}\text { Cachet } \\
\text { promedio } \\
\text { en pesos }\end{array}$ & $\begin{array}{l}\text { Cachet } \\
\text { promedio en } \\
\text { dólares* }\end{array}$ & $\begin{array}{l}\text { Porcentaje del } \\
\text { presupuesto destinado a } \\
\text { honorarios artísticos }\end{array}$ & $\begin{array}{l}\text { Porcentaje del presupuesto } \\
\text { destinado a otros rubros }\end{array}$ \\
\hline $1^{*}$ & 2013 & 500 & 82 & sin datas suffcientes & sin datos suficientes \\
\hline $2^{*}$ & 2014 & 600 & 70,5 & sin datos suficientes & sin datos suficientes \\
\hline $3^{*}$ & 2015 & 800 & 82,5 & $50 \%$ & $\begin{array}{l}\text { Producción y comunicación } 9 \% \text {. } \\
\text { grífla } 4 \% \text {, otros } 5 \%\end{array}$ \\
\hline $4^{*}$ & 2016 & 1000 & 62 & sin datos sufcientes & sin datos suffientes \\
\hline s* & 2018 & 5000 & 244 & $72 \%(73,5 \%)^{* *}$ & Grafica $11 \%$, otros $2 \%$ \\
\hline $6^{*}$ & 2019 & 15000 & 356 & $54 \%(72 \%)^{* *}$ & $\begin{array}{l}\text { Grafica 6\%: Prensay } \\
\text { comunicacion } 12 \% \text {; Alquiler de } \\
\text { sala elementos de utileria y } \\
\text { técnica } 2 \%\end{array}$ \\
\hline
\end{tabular}

TABLA 2: Cachet promedio por obra (en pesos y en dólares), porcentaje del presupuesto total destinado a honeraries artisticos $y$ porcentaje destiaade a otros rubres para las sucesivas ediciones del Festival Danzafuera.

"Se realiab la conversión considerando el valor del doblar al dia de inicio del festival.

*Entre partebesis se indica el porcentaje correspondiente inclayendo los gastos de alojamiento y alimentaciln de les artistas

Además de las diferencias en los montos totales movilizados por el festival, observamos que en estas tres ediciones el pago de honorarios artísticos oscila entre el 50 y $72 \%$ y el porcentaje restante se destina a otros rubros y/o profesiones. Cabe destacar que varios de estos otros rubros fueron cubiertos por artistas (bailarinxs y actorxs) que además se desempeñan en áreas técnicas, fotografía o realización visual, de modo que algunos de estos otros recursos también circularon por dentro de la comunidad de las artes escénicas platenses.

Es interesante señalar que los montos recibidos para el pago de cachets se incrementaron notablemente en las últimas dos ediciones gracias a la obtención del financiamiento del Programa Festejar, cuyo destino es específicamente el pago de cachets a los artistas participantes en festivales y encuentros.

Consideramos que los programas de subsidios de estas características son de gran importancia, y resultan una política pública novedosa ya que, como señala Mauro,

casi todos los sistemas de subsidios a las artes, a la cultura y a la investigación, contemplan insumos y gastos de producción, pero no los honorarios de los trabajadores, quienes no sólo llevan adelante el proyecto subsidiado, sino que además poseen cualidades y saberes específicos que constituyen un valor agregado irremplazable para que la obra o el producto final se realice (2018:116).

No obstante es curioso que aunque en términos del monto de cada cachet de lxs artistas se observa un aumento considerable, si lo analizamos en términos porcentuales, contrastando los montos destinados al pago de honorarios artísticos y aquellos destinados a otros rubros, el porcentaje se mantuvo (con la excepción de un aumento porcentual considerable en la quinta edición). Es decir, que así como se aumentó el cachet de los artistas, aumentó también la cantidad de recursos que se destinaron a otros fines.

En el caso específico de la última edición, cabe aclarar que de ese otro $50 \%$ cerca de un $20 \%$ se destinó a alojamiento y comida. Es decir que aunque se está nutriendo otros campos, también repercute en beneficios para lxs artistas. 
Por otra parte, cabe mencionar que el referido subsidio del Programa Festejar no contempla el pago de honorarios para las organizadoras del festival, que son en el caso analizado quienes aportan la mayor parte del trabajo. En este sentido, es interesante señalar la creciente presencia de los roles ligados a la gestión en el campo que nos encontramos indagando. Incluso cuando se trata de un un circuito que históricamente se ha caracterizando por la multiplicidad de roles ejercidos por sus participantes, consideramos que en los últimos años la gestión cultural es una actividad desarrollada de maneras cada vez más complejas por lxs mismxs artistas que, en otros ámbitos de su ejercicio profesional, continúan desempeñandose como intérpretes y creadorxs de obras. La creciente presencia de la gestión cultural por fuera del Estado y los privados se podría estar reflejando, por ejemplo, en la apertura, en las últimas décadas, de una serie de carreras de grado y posgrado que ofrecen formación en dicha disciplina. Esto da cuenta de un panorama que se complejiza, por un lado por los modos en los que el Estado delega la creación de políticas culturales en un sector que ofrece su trabajo en forma prácticamente gratuita, por otro lado, porque da cuenta de un frente importante en el que analizar la precariedad del trabajo artístico.

Por último, si bien los números que hemos compartido resultan ilustrativos sobre el modo en que se distribuyen los recursos monetarios, creemos que no dan cuenta del costo real del festival, sino únicamente de los montos de dinero que sus organizadoras manejaron de modo directo.

Si se tuviera en cuenta el valor económico de todos los recursos movilizados, muchos de los cuales se ceden en préstamos, se dan en canje, etcétera, como así también las horas de trabajo de todas las personas involucradas, y el dinero que, como mencionamos anteriormente, el Estado ahorra al apropiarse simbólicamente de la oferta cultural que ofrece Danzafuera, el costo del Festival aumentaría considerablemente.

Creemos que es importante seguir indagando en los modos en los que se distribuye y circula el valor de todos estos otros recursos en la gestión del arte y la cultura en este tipo de escenarios complejos que dan cuenta de la articulación de una gran cantidad de roles, actores, sectores e instituciones. 


\section{Bibliografía}

» Bourdieu, P. (2003 [1971]). “El mercado de los bienes simbólicos”. En Creencia artística y bienes simbólicos. Elementos para una sociología de la cultura. Córdoba y Buenos Aires: Aurelia Rivera.

"Baranchuk, M. (2016). Los trabajadores de los medios y sus organizaciones. Buenos Aires: Patria Grande.

»Basanta, L. y del Mármol, M. (2017). "¿Y si lo hobbie habita lo profesional? Apuntes sobre el trabajo en el teatro independiente platense." En Ansaldo [et al.] (Comp.). Teatro independiente: historia y actualidad, CABA: Eds del CCC.

» Basanta, L. y del Mármol, M. (2018). "Por qué hacemos lo que hacemos. Apuntes sobre deseo, reconocimiento y legitimación en la producción de teatro platense". Ponencia en las $2^{\circ}$ Jornadas de Estudios sobre Teatro Independiente Instituto de Artes del Espectáculo, FFyL, UBA. Septiembre de 2018.

» Bataille, G. (1987 [1933]). “La noción de gasto”. En La parte maldita. Precedida de La noción de gasto. Barcelona: Editorial Icaria.

"Boltanski, L. y E. Chiapello [1999 (2002)]. El nuevo espíritu del capitalismo. Madrid: Akal.

»Chapman, A. (1982). Los selk'nam. La vida de los onas. Buenos Aires: Emecé editores.

» del Mármol, M. (2020). “Entre el deseo, la amistad y la precarización. Trabajo artístico y militancia cultural en la producción teatral platense”. Cuadernos De antropología Social. En prensa.

" del Mármol, M. (2016). Una corporalidad expandida. Cuerpo y afectividad en la formación de los actores y actrices en el circuito teatral independiente de la ciudad de La Plata. Tesis doctoral. Facultad de Filosofía y Letras, Universidad de Buenos Aires.

》 del Mármol, M., Magri, M. G., \& Sáez, M. L. (2017). “Acá todos somos independientes: Triangulaciones etnográficas desde la danza contemporánea, la música popular y el teatro en la ciudad de La Plata”. En El genio maligno. Número 20.

" del Mármol, M. y Sáez, M (2020). Danzafuera. Impulsos de escritura II. La Plata: Club Hem Editorxs.

» Kunst, B. (2015a). Artist at Work: Proximity of Art and Capitalism. Winchester, UK y Washington, USA: Zero Books.

»Kunst, B. (2015b). “Las dimensiones afectivas del trabajo artístico: la paradoja de la visibilidad." En Rozas, I. y Pujol, Q. Ejercicios de ocupación. Afectos, vida y trabajo. Barcelona: Mercat de les flors / Institut del Teatre / Ediciones Polígrafa.

» Lorey, I. (2006). “Gubernamentalidad y precarización de si. Sobre la normalización de los productores y productoras culturales". EIPCP (Instituto Europeo para Políticas Culturales Progresivas), [en línea]. Consultado el 11 de abril de 2019 en http://www.eipcp.net/transversal/1106/lorey/es

" Mauro, K. (2018). "Entre el mundo del arte y el mundo del trabajo. Herramientas conceptuales para comprender la dimensión laboral del trabajo artístico". telondefondo Revista de Teoría y Crítica teatral. Año XIV, № 27. (en línea). Consultado el 20 de febrero de 2019. Disponible en <http://revistascientificas.filo. 
uba.ar/index.php/telondefondo/article/view/5097>.

»Merlos, L. B. y Sáez, M. L. (2017). “La danza habitando la ciudad Experiencias platenses en espacio público". En Reflexión académica en diseño y comunicación. Año XVIII, Vol. 31, Agosto 2017, Buenos Aires, Argentina, 190-200.

»Merlos, L. B. y Sáez, M. L. (2016). “Arte y ciudad: experiencias de danza en el espacio urbano”. ERAS Revista Europeia de Estudos Artisticos, 7(3), 65-93.

»Sáez, M. L. (2018). "Sobre la sensibilidad de los bailarines contemporáneos independientes. Apuntes a partir del '29A' en la ciudad de La Plata, Argentina”. En del Mármol, Ma.; Sáez, M,; Sanabria B., Carlos Eduardo (Eds.). Estética, sensibilidades y emociones: Actas de la Mesa 14. Encuentro Latinoamericano de Investigadores sobre Cuerpos y Corporalidades en las Culturas. La Plata: Investigaciones en Artes Escénicas y Performáticas.

» Sáez, M. L. (2017). Presencias, riesgos e intensidades. Un abordaje socio-antropológico sobre y desde el cuerpo en los procesos de formación de acróbatas y bailarines/as de danza contemporánea en la ciudad de La Plata. Tesis Doctoral. Facultad de Filosofía y Letras, Universidad de Buenos Aires.

»Sáez, M. L. (2016). “Potencia de la contradicción”. Revista boba.

» Sáez, M. L. (2015). “Tensiones y articulaciones en torno al concepto de 'independiente' en el campo de la danza contemporánea en la ciudad de La Plata”. Ponencia presentada en las II Jornadas de Reflexión sobre Creación Coreográfica en Danza. Facultad de Bellas Artes, Universidad Nacional de La Plata.

» Sáez, M. L., y López Betancourth, E. (2018). Danzafuera. Impulsos de escritura. La Plata: Club Hem Editorxs. 